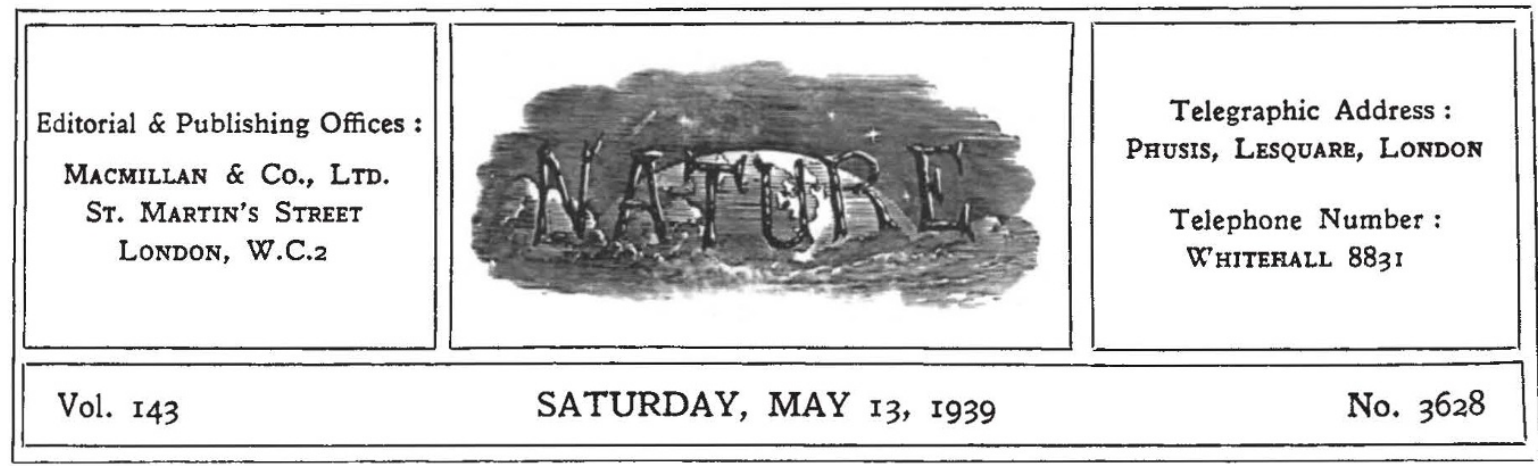

\title{
Establishment of New Industries
}

$\mathrm{T}^{\mathrm{n}}$ HE major proposals of the report on the location of industry recently issued by Political and Economical Planning (P E P) have already been outlined in these columns (NATURE, May 6, p. 770). From discussions of the report and its contents, however, it is apparent that a number of points raised by it are being overlooked. Among such matters of special interest to scientific workers is the suggestion that the proposed Industrial Development Commission should be empowered to advance money for the promotion of new industrial enterprise. This problem is discussed in some detail.

To a large extent the provision already made by the Special Areas (Amendment) Act of 1937, the Nuffield Trust and the Special Areas Reconstruction Association, Ltd., meets the need of new factory enterprise which is concerned with the manufacture of an established product or of a product not already made in Great Britain. The manufacture of an entirely new product or the establishment of a novel process is another matter, and the comments of the report on this subject may well raise doubts as to whether the Committee on Industrial Development, in its report issued in 1932, was not much too confident that there was no gap in our existing structure for the finance of development and research.

The present report does not consider that the difficulties in the way of developing entirely new processes or inventions are altogether the fault of financial institutions. Moreover, the few companies which have been formed specially to deal with new inventions do not appear to have had any great measure of success ; the necessary link between invention and finance has not yet been forged.
One of the major difficulties is the aggregate cost of 'vetting' new propositions, which frequently exceeds the profits to be anticipated on the small proportion of successful ones. The high cost is due to the difficulty of finding any firm or organization capable of dealing with the wide range of industries into contact with which a concern attempting to finance new processes is usually brought. The difficulty has been recognized, of course, for many years, and in November 1935 the Chancellor of the Exchequer made an important statement putting the Department of Scientific and Industrial Research, the Medical Research Council and the Agricultural Research Council at the disposal of banks, issuing houses and brokers to furnish them with reports on the scientific merits of the methods or substances for the development of which it might be proposed to make a public issue.

While, however, the three research organizations in question could undoubtedly be of far greater use to industry and finance, it is at least open to doubt whether they possess invariably the necessary combination of commercial and technical outlook. The nature of their responsibilities limits them to making a complete and exhaustive report on a technical subject. What is often required, however, is a quick opinion based on sound judgment and wide knowledge as a basis for a decision whether to proceed with further investigation or to reject the project at an early stage. The commercial prospects as well as the technical soundness of the process must be taken into account, and the appreciation required must consist not merely in the verification of technical claims but also in forecasting the demand for the new product, and the forces which determine it, 
the output of competitive products, the location of manufacture, the areas or industries in which they are sold, relative costs and selling prices, patent aspects, and other economic and technical factors.

At least it may be held that the establishment of the information service recommended in the P E P report should assist in dissipating the very serious lack of technical knowledge in financial circles, which may be regarded as responsible for its failure to restrain or check the excessive overcapitalization of new companies. Moreover, if the view is correct that the evolution of better facilities for the finance of new industries would be an important contribution to the problem of the Special Areas, it should be of no less service to areas which are in danger of becoming depressed through their dependence on a limited number of industries. It is therefore considered that stimulation of private enterprise in co-operation with Government enterprise may offer a solution. The proposed Industrial Development Commission accordingly should explore with business men the possibilities of setting up one or more specialized institutions to deal with the financing of new enterprises generally, and should be empowered to subscribe a proportion of the capital of any such institution. If the machinery then erected became effective and wide enough in its scope, the necessity for direct financing by the Commission of individual enterprises would be materially reduced and might eventually disappear.

There is yet another direction in which the report suggests the need for investigation by the proposed Commission. Any truly scientific policy of industrial development must take account also of both the preservation and restoration of amenities. Even with the examples of the depressed areas in front of us, as well as the encroachment on amenities which on a smaller scale is taking place all over the country, it is no simple matter to decide just how best to provide the necessary safeguards without unduly hampering industrial expansion.

The report itself recommends that the Com. mission should be given discretionary powers to attach conditions to licences, Qbliging manufacturers to provide for the safeguarding of local amenities or their restoration, if damaged or destroyed. This is one of the most important services that the Commission could render to the community; the widespread destruction which has resulted in the past from unrestricted development by private enterprise is sufficient indication of the need for preventing such destruction in future.

The mere institution of licensing powers should assist, for the Commission would consider this factor along with others in handling applications for licences. The efforts of public authorities to preserve amenities through town planning regulations should be substantially reinforced by this fact alone. Public policy, however, can do little or nothing to deal with the root cause of such nuisances as arise from the decline of the industry or enterprise itself and its eventual abandonment. It is possible, nevertheless, to take steps in advance to prevent the repercussions on local society as a whole from becoming too drastic. The report suggests that one way of dealing with this problem would be by means of a sinking fund.

This again is a matter for investigation by the Commission. Any such fund should be earmarked for the restoration of local industrial and social amenities, where necessary, in the future transfer or liquidation of any factory. The other aspect of this question-the extensive salvage operations which are already necessary to restore certain areas to a condition in which they can again become usable for industrial and social purposes-equally falls within the orbit of the Commission. Restoration of such areas should have an early claim on any Government funds available for general public works purposes, and the Commission would be the most suitable body through which the planning of restoration projects and the distribution of funds to local authorities could be carried out. In this respect, indeed, it would develop the pioneer work of the Commissioners for the Special Areas.

The suggestions of the report regarding these two problems, which are by no means so far separated as might appear at first sight, well illustrate its admirable balance. The care for industrial development is never allowed to overshadow the fact that the efficient utilization of the resources of the nation involves safeguarding the health and social well-being of its citizens and the natural amenities of the country. The exposition given in the report of the need for further scientific investigation in these matters, no less than the vision it gives of the possibilities if industrial development and the erection of new towns are viewed in their true perspective as creative social enterprise, will be widely welcomed. Nor does the report leave scientific workers in any doubt that they may well be called to make a decisive contribution, if these possibilities are to be realized. 